"This is an original accepted manuscript / preprint of an article published by Taylor \& Francis in South East Asia Research on 8 April 2019 available online: https://doi.org/10.1080/0967828X.2019.1587925

Accepted version downloaded from SOAS Research Online: http://eprints.soas.ac.uk/31576

\title{
Area Studies and the importance of somewheres
}

Michael Hutt, Professor of Nepali and Himalayan Studies, SOAS University of London E: $\underline{\text { mh8@soas.ac.uk } 1}$

The exotic field is everywhere... it is simply 'place', that second home of geography. (GibsonGraham 2004: 417)

This is a reflection on the decline of 'Area Studies' in the Euro-American academy. Area Studies has usually been characterised as a combination of two things: in-depth knowledge of a particular region or society (including, crucially, linguistic and cultural fluencies); and excellence in the practice of an academic discipline in relation to that region or society. Although it is sometimes presented and discussed as if it was a discipline, I believe it may be easier to chart an afterlife for Area Studies if we conceive of it as a multidisciplinary field that is predicated upon the significance of place and context, and on the importance of somewheres.

The combination of linguistic and disciplinary expertise that has been held up as the ideal form of Area Studies resembles very closely the core of the work done at my home institution, SOAS, in relation to Africa, Asia and the Middle East over the past 100 colonial and postcolonial years. However, the academic regionalisation of the world and the Area Studies approach that is based upon it have come under increasing challenge in recent decades, with the result that Area Studies and the study of languages and cultures have experienced a serious decline not only at SOAS but all across the Euro-American world. While Area Studies researchers take it as axiomatic that place matters when social, economic, political and cultural processes are discussed and analysed, part of the reason for the decline of Area Studies may be the problematic nature of its definition of 'place'.

First, there are the geopolitical anxieties. In the US in particular, Area Studies is seen as a product of the Cold War, designed to supply the Euro-American world with information on potential enemies. Indeed, even some of those who wish to see the old Area Studies centres and programmes maintained still attempt to play a kind of post-Cold War security card. At SOAS I have often heard pleas for the maintenance of specialist language provision that are based on arguments such as 'we are engaged in military action in Afghanistan but we don't have any Pashto lecturers'. This seems to assume that if we did have some Pashto lecturers the West's engagement with Afghanistan would be more sensitive and nuanced. It would be kind to call this naive.

\footnotetext{
${ }^{1}$ This paper is based on a keynote lecture on the Case for Nepali Studies given at Cornell University on 28 April 2017
} 
Second, there is the anxiety that some Area Studies programmes may be little more than public relations services for nation states and diasporas. In their introduction to the 2002 book Learning Places, Harootunian and Miyoshi discuss the example of Japanese studies, funding for which is enhanced in the US by bodies closely linked to the Japanese government. Since Japan's emergence as a global economic competitor, say Harootunian and Miyoshi, such bodies seek to accomplish 'the encouragement of Japanese studies by foreigners and the establishment of the unquestioned primacy of native authority' (2002: 3) while establishing 'the hegemony of Japanese funding for the dissemination of Japanese studies' (ibid.)

As the famous 'right side up' Himal map of South Asia shows, ${ }^{2}$ even if we accept the regionalisation of the world we have inherited, we may take different perspectives on any given Area. But there are still serious concerns about the very concept of an Area in this context. The division of the world into academic regions involved drawing lines on the map in an imperious neo-colonial way, often following the borders of the new postcolonial states. This academic regionalisation of the world is external to the areas concerned, because it emanates from the Euro-American world, which does not really conceive of itself as an Area at all. In the early years of Area Studies, the 'field' in which 'fieldwork' was to be conducted was always situated outside Euro-America, and the 'field' was a space that would be filled by something called 'development' which was conceptualised and designed elsewhere (Harootunian and Miyoshi 2002: 7). The emergence of Area Studies has therefore been linked by many to the reinforcement of the imperial-colonial relationship.

Area Studies is also attacked for creating conceptual empires that are to be thought of as homogenous and self-contained, when in fact they are neither. In his much-cited 2002 article, 'Geographies of knowing, geographies of ignorance', Willem van Schendel identifies four Himalayan or sub-Himalayan settlements that lie within 50 kilometres of each other but fall inside the corners of four separate 'academic regions'. Our academic engagement with individual cultures and societies within the 'Areas' demarcated by Area Studies is vulnerable to a reduction in political and institutional commitment when those cultures and societies are not seen as central to that Area. We Nepal specialists are well aware of the 'mandala-like structure' of South Asian area studies, in which Nepal sits in the 'cartographically peripheral' outer reaches. As van Schendel puts it, 'those who produce specialist knowledge about these places may occasionally be invited to court, but they will never be a part of the power elite' (2002: 651). And we should be wary of statements such as 'South Asia is a region of great cultural diversity.' Why would it not be? This is only the consequence of where our colonial forebears drew the lines.

It is further alleged that Area Studies fragments and fractures what should be a truly global conversation. Harootunian and Miyoshi accuse it of seeking to close off the study of particular units from the rest of the world, and contrast it with the newer discipline of Cultural Studies, which, they claim, examines such units in a more open context (2002: 8). van Schendel agrees that Area Studies has hampered information flows: 'today a Latin Americanist listening in on a conference of Africanists, or a scholar of the Middle East among Southeast Asianists, feels rather like an Anglophone African at a meeting of Francophone co-continentals' (van Schendel 2002: 648).

\footnotetext{
${ }^{2}$ https://himalmag.com/the-right-side-up-map-of-southasia/
} 
All of these criticisms of Area Studies are valid. Unfortunately, they have an increasing tendency to spill over into an assault on any kind of close academic engagement by EuroAmerican researchers with other cultures or societies. Most dangerously, it is argued that globalisation makes this kind of engagement redundant. Harootunian and Miyoshi write, 'As globalization thickens, the site of research grows increasingly mobile' (2002: 1). Area Studies, they say, has 'outlived the original reason for its construction and has become an entrenched structure that maintains the separation of area expertise from general knowledge' (2002: 6). This represents a 'missed opportunity to make the study of a specific area part of the general learning of the world' (ibid.). It is also alleged that Area Studies fetishizes language learning and that in Area Studies centres translation is 'not only the preferred model of scholarly activity but... the sign of having acquired the only method needed, which is learning the language' (2002: 12).

And it is indeed true that in the more leisurely past Euro-American scholars of Africa, Asia and the Middle East often pursued academic careers in which a region was their primary, and sometimes their only, point of identification. They underwent the painstaking process of learning a language first, before developing skills in a discipline-if indeed they did the latter at all. A recent institutional history of SOAS describes how for the first fifty years of its existence the School was essentially a school of languages, structured around regions, with History and Linguistics the only departments defined by specific disciplines. Social science departments were established only in the 1960s, and their faculty members were treated with contempt by many of the regionally organised language specialists, who regarded them as little more than overqualified journalists (Brown 2016).

But the shape of SOAS has changed radically over the past 20-30 years, and with it the pattern of faculty training and development. Ideally, Area Studies scholars were supposed to be produced through a process of training in which the disciplinary and linguistic strands of their education proceeded in parallel. Nowadays, however, the disciplinary training increasingly takes precedence, with a decreasing amount of time and resource dedicated to linguistic and cultural training. I fear that we may already be sending doctoral students out to Africa and Asia armed with a sophisticated understanding of French cultural theory but the ability to do little more in the local language than order a cup of tea.

The production of Area Studies scholars is a time-consuming and expensive process and not much of it can be done in large, surplus-generating lecture theatres. This fact, coupled with the dramatic growth of economic and financial globalisation, international migration and deterritorialised identities, encourages those who believe that Area Studies merely fetishizes the local and is theoretically vacuous, and that globalised disciplinarity is enough. To put it simply: some say these days that there is no case, either financial or ideological, for the publicly-funded development of in-depth scholarly expertise on faraway lands.

But even if the Area Studies framework is redundant, the world still needs scholars who (as Michael Kennedy put it twenty years ago) know a society other than their own 'in a deeper way than translations and questionnaires allow' (Kennedy 1997: 3) Otherwise, all scholarly collaborations between the unmarked West and the Area-ed and regionalised Rest will boil down to little more than 'the dangerous syndrome of data for dollars' (ibid.), in which raw material from the Rest is imported to expand the theoretical capital of the West. 
This presumption of what Kennedy calls 'intellectual centering in the West' (1997: 4) is highly problematic. First, it assumes that scholars born and trained in geographies and cultures other than those of Euro-America have little to contribute to the scholarly debates and concerns of Euro-America. Second, it forgets that the disciplines around which EuroAmerican learning structures itself were themselves conceived by particular people in particular places and leaves those people's 'local knowledge culture' unscrutinized. Third, it assumes that scholarship published in non-Euro-American languages has a currency that is of limited and purely local salience. This is at least as colonialist an attitude as the one that divides the non-Euro-American world into Areas.

Of course, some aspects of research on globalisation do have to take place at a level of generalisation that is higher than regional frameworks. But every question has an appropriate scale, and the greater the scale of the question the broader and more superficial the answers will be if these are not moored - somehow, somewhere, in some place-in the granular detail of grounded empirical research. For instance, do we need to understand not only the impact of global economic and cultural flows on Indian society but also the extent to which India itself serves as the origin of globalising forces? I think so, for all sorts of reasons, and I believe this is widely recognised. Can we do so without conducting research in India itself? I think not. Should we produce scholars with the linguistic and cultural fluencies and disciplinary expertise needed for this? And should those scholars collaborate with Indian scholars to conduct this research, and attend to what is written and spoken in Indian languages as well as English? Well, if they do not then we will be working with understandings that may be theoretically sophisticated but are not anchored in any place and are at serious risk of being superficial.

Jorges Dominguez has made a strong case for the potency of combinations of specific disciplinary and specific regional expertise and the importance of what he calls 'somewheres'. Dominguez writes as follows,

'Area studies political science is not an oxymoron. It presumes that scholars interested in the study of politics somewhere would value the particularities of that 'somewhere' as they frame the questions, hypotheses, and research instruments and procedures that they will employ. It equally presumes that they have read, pondered, internalized wherever appropriate, and otherwise learned in various ways from a wide array of fellow scholars who have worked in other 'somewheres' with different research instruments and procedures and contrary hypotheses or analytic frameworks. Area studies political scientists seek to contribute to the analysis of the somewhere that has been the principal object of their research and also to the wider analytic and empirical study of comparative politics' (Dominguez 2009: 180).

All people come from a geographical, historical, cultural, ethnic and linguistic somewhere, even if they now live in a somewhere else. But we do not need to adopt the colonial division of the world into academic regions to study and understand the differing contexts in which humankind creates its meanings. Given the constraints of human mortality, it is impossible for any scholar to become a true 'specialist' for the whole of any Area, whatever his or her origins. No peoples or societies self-identify with any of the Areas defined by EuroAmerican scholarship. Area Studies centres claim but inevitably fail to offer regional coverage, and many exhibit a growing tendency towards methodological nationalism. So maybe we should abandon the Areas and seek a different unit of context, without obviating 
the need for students, teachers and researchers to engage intensively with societies other than their own. Let us seek instead a linguistically informed, multi-disciplinary focus on a range of different 'somewheres' that provides lessons for us, and for the people of each and anywhere, about the topics that interest us and the challenges that face us all.

\section{References}

Brown, Ian 2016. The School of Oriental and African Studies: Imperial training and the expansion of learning. Cambridge: Cambridge University Press.

Dominguez, Jorges I. 2009. 'Don't stay home. The utility of area studies for political science scholarship' in The Future of Political Science: 100 perspectives, edited by Gary King, Kay Lehman Schlozman, Norman H. Nie. New York and London: Routledge, pp. 180-2.

Gibson-Graham, JK 2004. 'Area studies after poststructuralism' Environment and Planning 36: 405-19

Harootunian, HD and Masao Miyoshi 2002. 'Introduction: 'The 'Afterlife' of Area Studies' in Learning Places. The Afterlives of Area Studies. Edited by Masao Miyoshi and H.D. Harootunian. Durham and London: Duke University Press, pp. 1-18.

Kennedy, Michael D 1997. 'A Manifesto (of sorts) for Area Studies' Journal of the International Institute 4.3: 1-8.

van Schendel, Willem 2002. 'Geographies of knowing, geographies of ignorance: jumping scale in South-east Asia' Environment and Planning 20.2: 647-68. 